\title{
Emergency preparedness and operational response: a Spanish case study within the European Union Framework
}

\author{
A. García-Miravete \\ TRAGSA, Spain
}

\begin{abstract}
The primary emergency response to a particular disaster will only minimize its overall impact when two factors operate efficiently: rapidity and proportionality.

After a thorough threat assessment on the level of risk that Spain faces regarding natural or man-made disasters, TRAGSA's emergency management system can be recognized as an effective and efficient solution for immediate response. (TRAGSA is the Governmental Agency (Public Company) in charge of rural development, environmental protection and emergency management.)

Within the context of limited resources and the need for an operationallyoriented policy mainly focused on the identified priorities, our emergency management system for environmental disasters does offer reasonable satisfaction in terms of rapidity and proportionality.

We intend, therefore, to explain how to achieve the best possible results (quick and proportionate) in a crisis scenario with environmental impact (from those identified within the National security strategy) occurring in any territory of a country 500,000 square kilometres wide. To that end, we will show how the model has behaved in real scenarios.

The involvement of the civil agency for environmental catastrophes (TRAGSA) is providing adequate answers to the incident regardless of the magnitude and place of occurrence, as it will be shown in the case studies.

The specific interest of this paper is to consider and communicate the idea of a "non stand-by approach and multifunctional team", that is to say, the way in which TRAGSA operates during emergencies.

The main strengths of the system are:

a) Rapidity of the response regardless the emergency location.

b) Proportional deployment according to the magnitude of the incident.
\end{abstract}


c) Accurate expertise and knowledge on the main emergency categories.

d) Effective and efficient use of "scarce" resources.

In conclusion, the purpose of our work is to present a tested and proven case study on emergency response management based upon recent real scenarios occurred in Spain, namely BOLIDEN (toxic waste in Guadalquivir river), ARENAS (severe forest wildfire) and ARRIONDAS (case of floods in Asturias) to demonstrate how the system offers rapidity, proportionality, expertise and economy, taking into account, in addition, the EU wider scenario that new regulations and strategy are shaping in Europe.

Keywords: emergency management system, European Economic Area (EEA), solidarity clause, civil protection mechanism, European civil protection modules, emergency response capacity, territorial deployment system, regional emergency coordinator, multi-functionality and specialization, non stand-by approach, close presence to the scene.

\section{Introduction}

"There is some evidence that climate change is contributing to the increasing frequency and intensity of weather related natural hazards. It is projected that these effects of climate change could intensify in the future" (European Environmental Agency (EEA) [1]).

Natural hazards and technological accidents occurred in Europe have been described in detail by the EEA. The report states that from 1999 to 2009 there were 100,000 fatalities affecting 11 million people and EUR 150 billion were lost in the 32 countries included in the European Economic Area (EEA [1]).

Regarding to natural hazards, particular reference should be made to floods in Central Europe in 2002 (over EUR 20 billion loss), in Italy, France, and Switzerland in 2000 (about EUR 12 billion loss) and in the United Kingdom in 2007 (over EUR 4 billion loss); the earthquakes in Izmit (Turkey) in 1999 (over EUR 11 billion loss) and L'Aquila (Italy) in 2009 (more than EUR 2 billion loss); winter storms over Central Europe in 1999 (more than EUR 18 billion loss) and 2007 (almost EUR 8 billion loss) (EEA [1]). 15,000 fatalities have been reported related to natural hazards during the considered period of time in the EEA.

Concerning Spain, significant forest wildfires do happen regularly during the summer (averaging 20,000 per year), as well as water scarcity and droughts (2003, 2005, 2006 and 2008). And the incidence of floods within the country has considerably increased in recent years $(2009,2010)$.

A larger impact on ecosystems has been produced, however, by technological hazards, namely oil spills of tankers Erika in the western coast of France (1999) and Navion Britannia in Norway (2007), or a cyanide spill in Baia Mare (Romania, 2000), among others. Industrial accidents have occurred in different countries having an impact on human lives and causing economic losses of around EUR 3.7 billion.

In Spain, the oil spill of tanker Prestige (2002) produced the most damaging technological accident in Europe during the studied decade (60,000 tons of fuel spread over the coast and sea of north-western Spain). 
In Puertollano (2003), an explosion and fire in a storage tank did result in seven fatalities and several more people seriously injured.

\section{The incoming scenario}

Taking this "decade scenario" into consideration, different security strategies within the European Union Countries have shown a primary focus on emergency management.

The current British National Security Strategy [2], issued in October 2010, recognizes four high priority risks for the next five years:

- international terrorism

- cyber attacks

- international military crises

- major accidents or natural hazards

The European Union Internal Security Strategy (European Union [3]), issued in 2010, sets out a European security model which "integrates action on law enforcement and judicial cooperation, border management and civil protection (...)" (Pérez Rubalcaba [4]), understanding the global concept of security "as a comprehensive one which straddles multiple sectors in order to address these major threats and other which have a direct impact on the lives, safety and wellbeing of citizens, including natural and man-made disasters such as forest fires, earthquakes, floods and storms" (EU [5]).

The Spanish Security Strategy (Solana et al. [6]) recognizes climate change as a major influence factor for certain threats within the Mediterranean habitat such as floods, droughts, wildfires and desertification. Moreover, the proximity to Africa, one of the most exposed areas in the world to this phenomenon, could aggravate the incidence of sanitary problems originated in this continent".

\section{The framework}

The Treaty of Lisbon, recognised in Europe as the highest legal instrument, contains a Title VII denominated "solidarity clause". Its article 222 declares: "The Union and its Member States shall act jointly in a spirit of solidarity if a Member State is the object of a terrorist attack or the victim of a natural or man-made disaster. The Union shall mobilize all the instruments at its disposal, including the military resources made available by the Member States (...)" (EU [7]).

Based on this high level legal mandate, the Stockholm Program has developed a "comprehensive and effective Union Disaster Management: reinforcing the Union's capacities to prevent, prepare for and respond to all kinds of disasters". To that end, the program calls for covering "the whole disaster cycle encompassing prevention, preparedness, response and recovery for actions both inside and outside the Union" (EU [8]).

The previously mentioned document highlights the need to strengthen the Union Civil Protection Mechanism (EU [9]), in particular through developing the modules system together with a proper training and exercise within certain geographical areas (Mediterranean, Baltic Sea, etc.). 
In March 2010, The European Union adopted its previously mentioned "Internal Security Strategy: Towards a European Security Model" [10] covering action on law enforcement and judicial cooperation, border management and civil defence. In particular, EU reaction to emergencies is projected to be guided by prevention and anticipation as well as further improvements in preparedness and response. "Guidelines for hazards and risk-mapping methods, assessments and analysis should be developed as well as an overview of the natural and manmade risk that the EU may face in the future" (Pérez Rubalcaba [11]).

In November 2010, the communication from the Commission to the European Parliament and the Council [12] named "The European Union Security Strategy in action: five steps towards a more secure Europe" sets an objective to increase Europe's resilience to crises and disasters, containing four specific actions:

1. Make full use of the solidarity clause

2. An all-hazards approach to threat and risk assessment

3. Link up the different situation awareness centres

4. Develop a European Emergency Response Capacity for tackling disaster.

According to the Spanish National law, TRAGSA is defined as the Agency (the notion of "state-owned company" under the Spanish National Law could be understood, within this context, as a kind of Governmental Agency) in charge of essential services in rural development, environmental protection and emergency management (Government of Spain [13]). To the latter end, all TRAGSA resources must respond, under official request, to any kind of emergency or civil defence need, particularly those related to environmental catastrophes. In addition, TRAGSA is legally entitled to take part as an institutional service in international cooperation.

\section{Purpose of the study cases}

The purpose of this paper is to communicate and disseminate examples of operational responses related to the emergency management system that TRAGSA (as a Spanish Civil Agency for Environmental Catastrophes) has planned, carried out and finally proven, based upon the methodological principles of "non stand-by" and "multifunctional teams" in order to reach rapidity and proportionality.

The overall Spanish system for emergency preparedness, response, mitigation and recovery is indeed a more complex product than the one reflected in this paper. In fact, several Agencies and entities participate in one or more phases of the disaster management system under the umbrella of the Civil Protection General Directorate, namely the Red Cross, certain NGOs, a military forces specialised unit or TRAGSA are included.

At this stage, TRAGSA is preparing its participation within the European mechanism for civil defence under the umbrella and guideline of the previously mentioned Civil Protection General Directorate an ultimately the European Commission. To show the proper alignment of the TRAGSA emergency management model with the defined European modules (EU [14]), a summary of the chosen scenarios is offered. Moreover, by reviewing these paradigmatic 
cases, the benefits of the model are underlined, in particular rapidity of action, proportionality and adequacy, expertise, effectiveness and efficiency.

In addition, particular reference will be devoted to the technological support tool EMERCARTO, a substantial improvement under permanent evolution that has become the real backbone of the overall emergency management system.

\section{Capabilities and working methodology}

As it was said, comprehensive emergency management system should be and will be composed of several acting bodies whose areas of expertise and responsibility within the emergency are diversified. Nevertheless, their proper coordination becomes a mandatory requirement and success will only be achieved if those involved have played the role for which they have been called.

Taking this into consideration, we make reference in this paper to certain capabilities with implementation in real scenarios that have offered added value and produced positive results.

The main strengths developed for emergency management are:

1. TRAGSA is composed of nearly 20,000 staff members deployed among the 17 regions and the 41 provinces in which these regions are divided.

2. Their regular activity, regardless of the place in which they are deployed, is related to environmental protection and rural development.

3. A territorial deployment system has been set up. Based upon the principle of "close presence to the scene" and "non stand-by approach", each of the regions keeps their own Emergency Coordinator and each province has a Province Emergency Manager, whose tasks are related to the preparedness and response of the overall subordinated staff. "Close presence" because they are properly and strategically deployed on the spot and "non stand-by" because they are all involved in alternative projects and tasks in such a way that, as soon as the emergency takes place, they are called for immediate response. According to the principle of "emergency priority" the system should be able to mobilize the appropriate staff in a flexible and effective manner.

4. According to the catalogue of actions in emergency management, TRAGSA has produced a scenario approach by classifying and allocating specialized resources to all possible cases:

a) Biological or sanitary alerts (diseases and plagues, epidemics and food poisonings, epizooties and animal mortality).

b) Hydro-meteorological hazards (storms, extreme temperature events, forest fires, water scarcity and droughts, floods).

c) Geophysical hazards (landslides, earthquakes and volcanic eruptions).

d) Technological hazards (oil spills, industrial accidents).

5. A systematic training program has been created and implemented in such a way that every staff member possibly attached to an emergency operation could be requested to follow his or her emergency development training module based on the multi-functionality and specialization principles.

6. The whole system revolves around the IT solution EMERCARTO, a geographic information system which contains a both material and human 
resources database with all relevant associated information and is split into different disaster scenarios, according to the previously mentioned catalogue. For each of them, the system offers alternative solutions for resource deployment and timetables, specialized official protocols, a list of similar previous cases and other significant variables which could influence the evolution of the case.

\section{Case study I (Aznalcóllar 1999)}

\subsection{Case description}

The breakage of a decantation pond in the mining site near Aznalcóllar, which happened during the late night of April 25th, 1998, spilled in Guadiamar River approximately $6 \mathrm{hm}^{3}$ of acid sludge and waters with a pH of about 5.5 and high concentrations of dissolved heavy metals. The affected surface was calculated to be 4630 ha, stretching $62 \mathrm{~km}$ with an average width of $500 \mathrm{~m}$, from the mining site to Entremuros, located in the North-East limits of Doñana National Park. The spill, while resulting in no personal damages, caused important socioeconomic and environmental damages, as every primary use developed in the area was heavily affected.

Mining activities were paralyzed, it was decided to eliminate affected crops and agricultural activities on affected soils were suppressed.

This incident was a challenge for Spanish Public Action, fronted with such a catastrophe. The first of its magnitude to happen in Europe demanding the formation of an exceptional regime of intervention, competing for both State (Federal) Administration and Autonomic (Regional) Administration.

\subsection{Unit deployment}

TRAGSA deployed from the beginning of the emergency (three hours after the warning) seven harrow-equipped tractors and three heavy duty vehicles.

An expert manager arrived on the spot in the morning of the April 26th. This deployment grew as the emergency developed during the following days, totalling: 23 people in directing and administrative tasks, 70 people in auxiliary tasks, 195 trucks, 79 heavy duty vehicles and 14 other vehicles. 8237 days' wages in handpicking work were summarised.

\subsection{Chronological evolution}

The spill expanded along Guadiamar River and its borders, towards Doñana National Park, where the river flows into.

The very first day of the incident, the containing wall in Vuelta de la Arena, in the Entremuros area, was reinforced so the contaminated water couldn't reach the limits of the Doñana National Park, accomplishing the objective to overcome the threat the following day, April 26th.

Afterward the collection of toxic sludge affecting the river course, its banks and the surrounding crops started being carried out. 


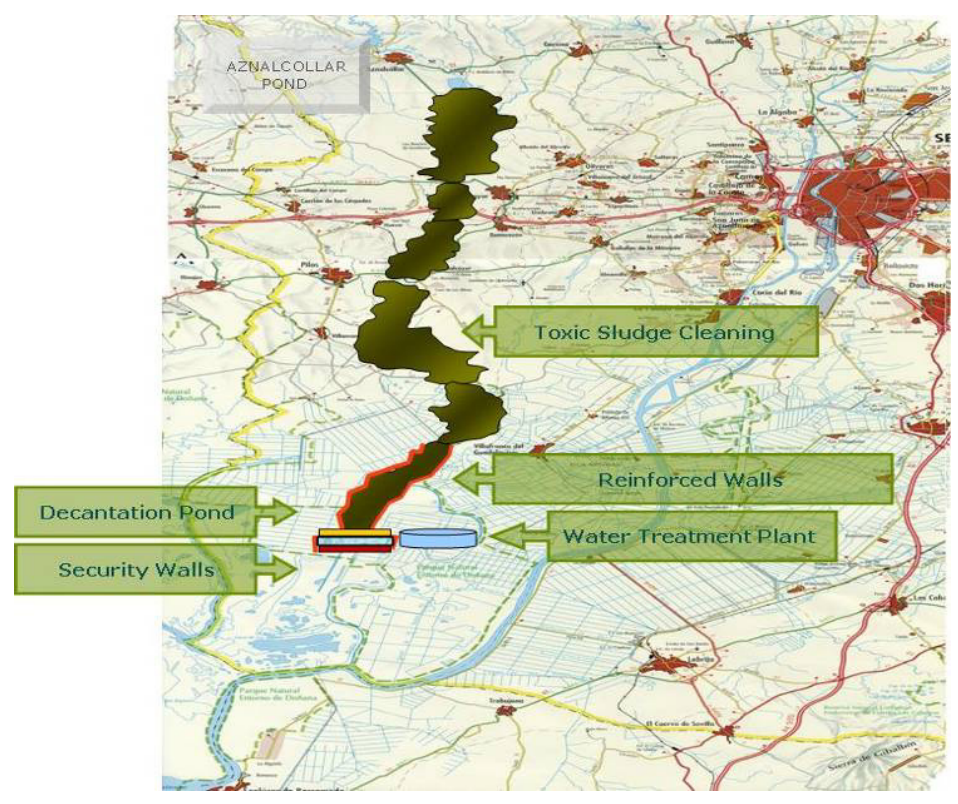

Figure 1: Affected area and taken actions.

Finally, 77 small dams were built along the river course, anticipating the Fall Guadiamar rises in the next level.

\subsection{Results}

The contamination of Doñana National Park waters and surrounding rice crops was avoided, thus accomplishing the primary objective.

Then TRAGSA executed the cleansing of the riverbed and banks, as well as the collection of toxic sludge with these results:

- River course cleaned: $17 \mathrm{~km}$

- River banks cleaned: $850,000 \mathrm{~m}^{2}$

- Mining materials collected: $188,000 \mathrm{~m}^{3}$

- Agricultural land cleaned: 1,414 ha

- Sludge volume collected: $640,000 \mathrm{~m}^{3}$

The depuration of acid waters was then addressed, with a second contention wall being built, as well as depuration plant and a decantation pond in Entremuros.

\section{Case Study II (floods in Asturias 2010)}

\subsection{Case description}

As a consequence of the heavy rains that took place during the middle days of June 2010 in Asturias Principality, important floods in coastal zones and population areas occurred, as well as an erosive dragging of all river courses, and 
the accumulation of the dragged material in river mouths and along the coastline Floods and dragging also resulted in breakdown of communication lines, important material damages and varied damages in urban areas and beaches.

TRAGSA acted in the flooded town of Arriondas, the cleaning of the coastline in different municipalities and the regeneration of affected river courses.

\subsection{Unit deployment}

TRAGSA deployed in Arriondas: 120 workers, 1 command team, 9 trucks, 19 dumpers, 4 heavy duty vehicles and 104 mixed vehicles and heavy equipment.

More than 3,500 working hours of specialised crew and more than 1,200 working hours of different vehicles and heavy equipment were mobilised.

\subsection{Chronological evolution}

In Arriondas, just three hours after being mobilized by the Government Delegation in Asturias Principality, TRAGSA deployed: 43 workers, a 3-people command team, 1 truck, 8 dumpers, 1 heavy-duty vehicle and 7 mixed vehicles.

In the following days TRAGSA would keep adding units until reaching the total reflected before.

\subsection{Results}

Arriondas was cleaned from mud and debris, fresh water services re-established and water pumped out from garages and basements. 14,785 tons of vegetal wastes were collected from coastlines and stored in a treatment plant. Damaged infrastructures were repaired and river courses restored (figs 2, 3).

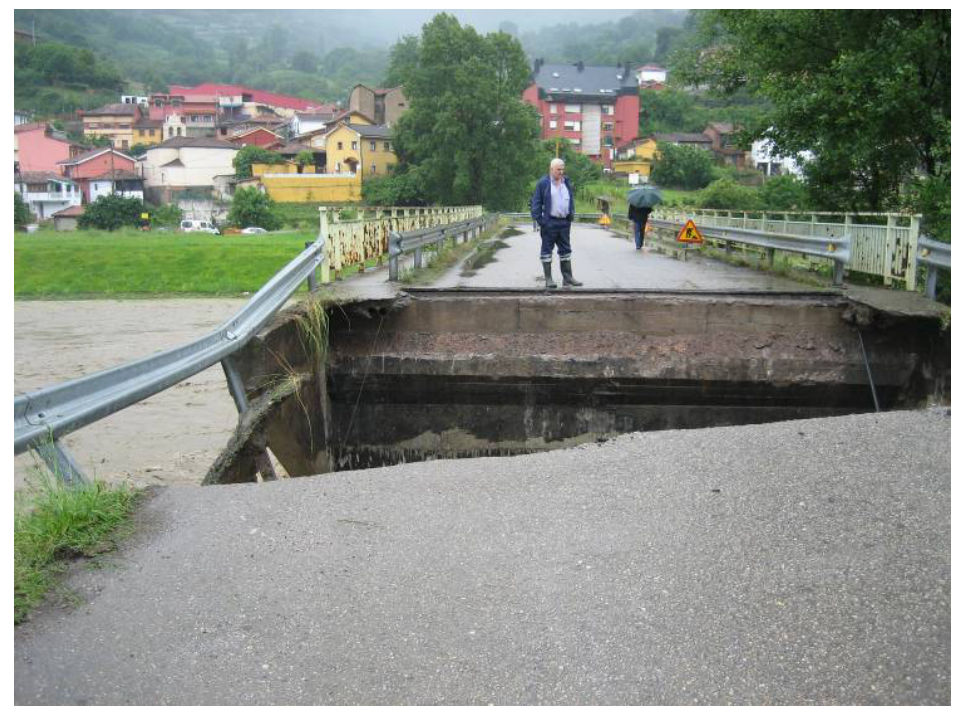

Figure 2: $\quad$ Affected communication lines. 


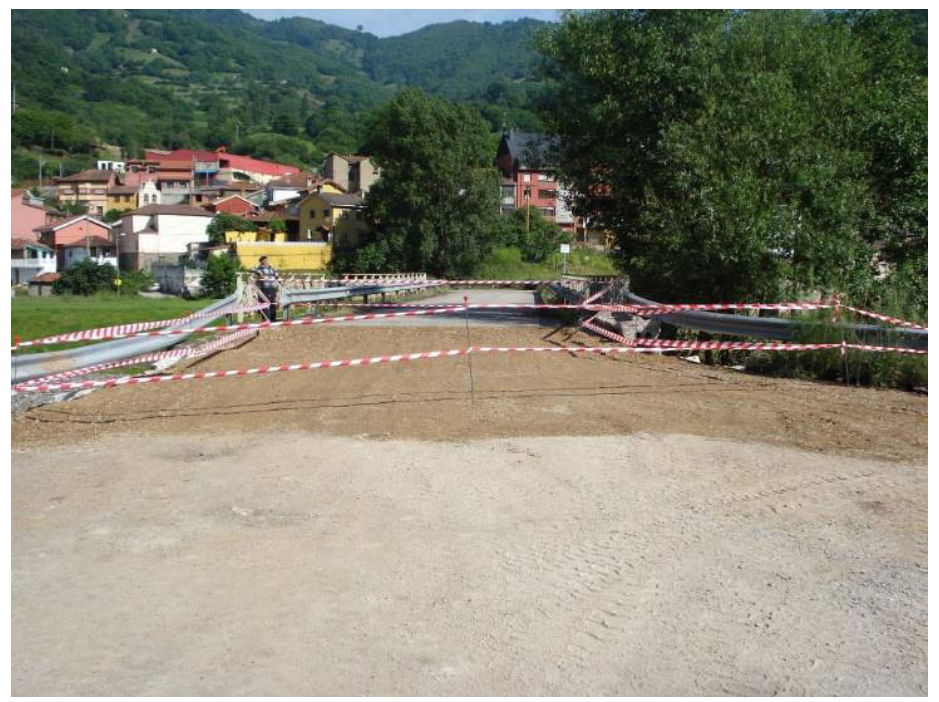

Figure 3: The same road, after TRAGSA intervention.

\section{Case Study III (wildfire in Arenas 2009)}

\subsection{Case description}

At 13:20 of July 28th, 2009, the Observation Post at La Sillita detected a forest fire in a pine area close to Arenas de San Pedro. The vegetation type (pine forest with heavy understory), the terrain orography with creeks and steep hillsides

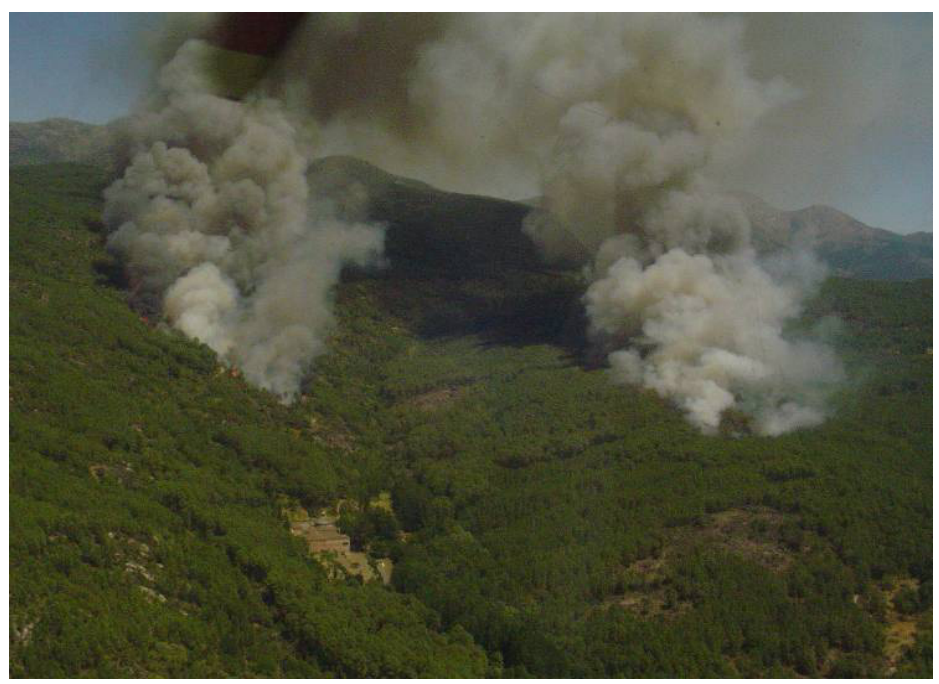

Figure 4: $\quad$ Both initial spots in the steep hillsides. 
added to the wind speed and direction and the time of day were all characteristics favourable to fast fire spread across creeks. In addition, the presence of two different initial spots (fig 4), predicted an extreme fire behaviour, thus the Ávila Fire Central Office immediately sent every available resource.

\subsection{Unit deployment}

From the very beginning every available fire fighting resources in the area was mobilized, including 4 TRAGSA-run Helitack crews which arrived to the fire within 20 minutes. More non-TRAGSA resources were mobilized, including 2 Helitack, 3 engines, 6 crews and a coordination helicopter.

During the development of the fire, which lasted four days, the following TRAGSA operated resources were deployed: 12 Helitack crews, including BRIFs, 17 crews, 1 coordinator, 3 heavy-duty engines and 5 attached Engineers.

\subsection{Chronological evolution}

The fire developed quickly taking advantage on steep hillsides and wind direction, developing in a crown fire on a fuel model 7, (Pinus pinaster with thick understory) thus complicating suppression efforts and resulting, despite the fast response times, in an uncontrolled fire which raged for four days, while suppression resources worked 24 hours a day.

\subsection{Results}

The fire was considered to be extinguished at 09:25 of July 31st, 2009

The affected area totalled 4211.74 ha, distributed between 3975.87 ha of forest terrains (fig 5), and 235.87 ha of agricultural lands.

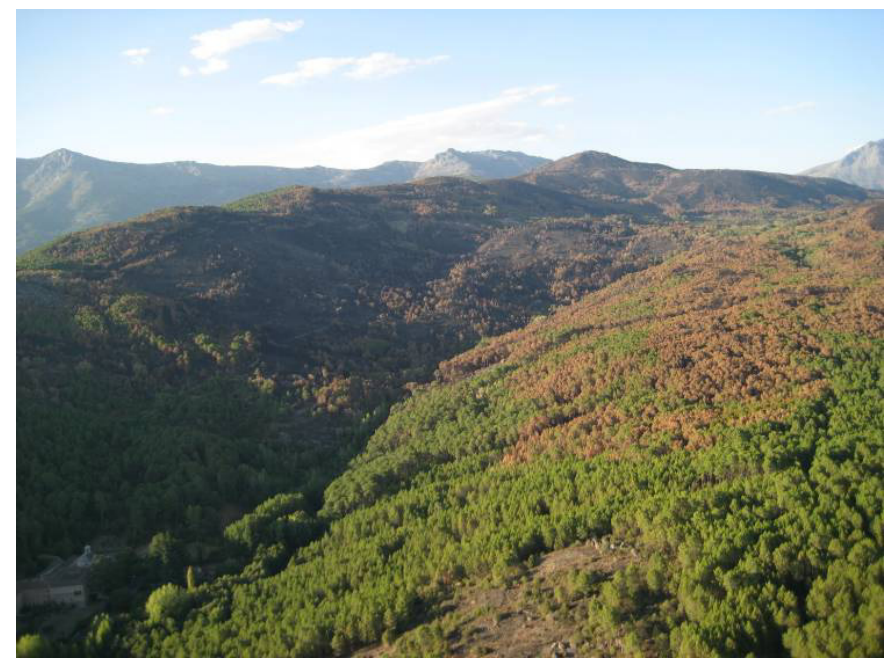

Figure 5: Affected area a month after the fire. Both initial spots are clearly visible. 


\section{Conclusions}

1. Natural hazards and man-made disasters represent an increasing threat to the economy, environment and safety of the citizens, existing evidence that climate change is contributing to this trend in terms of frequency and intensity.

2. Recently approved National security strategies, as well as EU internal security strategy, identify and forecast the impact that these potential disasters will have in the coming future, highlighting the need to set up action plans to counter its devastating effects.

3. Concerning the EU internal security strategy, the principle of solidarity, contained within the Treaty of Lisbon, and its further legal implementation represents a frame of reference when approaching strategies to combat emergencies.

4. TRAGSA is legally considered a specialized Agency in charge of fighting environmental catastrophes all over the Spanish territory whose working methodology is based upon the principle of "non stand by and multifunctional team". This means that the staff ordinary work is related to rural development projects and only when the emergency emerges the personnel is immediately reassigned to its fight. Multifunctional teams because they all follow a systematic training in different areas of specialization.

5. TRAGSA has recently been involved in the EU civil protection mechanism through participation in the implementation of different emergency modules being able to be displayed overseas when required.

6. Presentation of three significant cases is intended to show how diverse emergencies (heavy acid spill close to a protected area, heavy floods in rural/urban area and a severe forest wildfire) can be efficiently managed in terms of rapidity and proportionality, as stated in the first paragraph of our paper and taking into consideration TRAGSA working methodology: non standby approach and multifunctional team working. In addition, the support of the IT solution EMERCARTO as an organizational and geographicreferenced tool for emergency management has been underlined.

\section{References}

[1] Mapping the impacts of natural hazards and technological accidents in Europe. EEA Technical Report. No 13/2010. Publications Office of the European Union: Luxembourg. Page 8. 2010.

[2] A strong Britain in an Age of Uncertainty: The National Security Strategy. Presented to Parliament by the Prime Minister by Command of Her Majesty, October 2010. Online. www.official-documents.gov.uk/

[3] Internal Security Strategy for the European Union. Towards a European Security Model. European Council Meeting 25-26 March 2010. Brussels. 2010. 
[4] Foreword by the Spanish Interior Minister and President of the Justice and Home Affairs Council first half 2010, Mr Pérez Rubalcaba. Internal Security Strategy for the European Union. Towards a European Security Model. European Council Meeting 25-26 March 2010. Brussels. Page 5. 2010.

[5] Internal Security Strategy for the European Union. Towards a European Security Model. European Council Meeting 25-26 March 2010. Brussels. Page 8. 2010.

[6] Not yet official. Coordinated by Mr Javier Solana, former High EU representative for the Common Security and External Policy. Draft taken from: http://www.infodefensa.com/?noticia=solana-recomienda-a-zapaterola-creacion-de-un-consejo-de-seguridad-nacional

[7] Treaty of Lisbon, Title VIII, Article 222. Official journal of the E.U. C306. Publications Office of the European Union: Luxembourg. 2007.

[8] Stockholm Programme. Official journal of the E.U. C115. Publications Office of the European Union: Luxembourg, pp 25-26. 2010.

[9] Decision 2007/779/CE, Euratom. Online. Taken from: http://europa.eu/ legislation_summaries/environment/tackling_climate_change/ 2007.

[10] Internal Security Strategy for the European Union. Towards a European Security Model. European Council Meeting 25-26 March 2010. Brussels. 2010.

[11] Foreword by the Spanish Interior Minister and President of the Justice and Home Affairs Council first half 2010, Mr Pérez Rubalcaba. Internal Security Strategy for the European Union. Towards a European Security Model. European Council Meeting 25-26 March 2010. Brussels. Page 5. 2010.

[12] COM (2010) 673 final. Brussels 22.11.2010.

[13] Law 30/2007, of Public Sector contracting. Boletín Oficial del Estado, 261, Madrid, pp 44336-44338. 2007).

[14] Decision 2007/779/CE, Euratom. Online. Taken from: http://europa.eu/ legislation_summaries/environment/tackling_climate_change/ 2007. 